\title{
Enduring effects of periadolescent alcohol exposure on passive avoidance performance in rats
}

\author{
GUY L. OSBORNE and ARTHUR C. BUTLER \\ Carson-Newman College, Jefferson City, Tennessee
}

\begin{abstract}
Rats were administered alcohol during periadolescence (age 30-40 days) and then tested, beginning at 60 days of age, in an aversive-noise passive avoidance task. Relative to a low-dose group and to controls, the animals that had received a high dose were found to be impaired in this task. These results suggest that the developing juvenile is vulnerable to enduring effects of this drug. Thus, risk of impaired development due to alcohol may not be limited to the fetal and neonatal periods but may extend through later postnatal periods as well.
\end{abstract}

Since the thalidomide tragedy of the early 1960 s, much research has been conducted on the developmental toxicity of drug exposure during the prenatal and early postnatal stages of life. The extent to which later developmental processes in the juvenile are vulnerable to enduring change by pharmacological means would also seem to be of interest, in view of the facts that brain growth and functional maturation continue through adolescence (Schuster, 1980) and that drug abuse does occur among children (Cohen, 1976). While periadolescence is beginning to be recognized as a unique developmental stage in terms of characteristic behaviors and pharmacological responsitivity (Spear \& Brake, 1983), the question of long-term consequences of juvenile exposure to drugs with teratogenic potential remains largely unexplored.

Alcohol is a good case in point. The teratogenic potential of alcohol has been established by many studies which show that prenatal exposure may cause the fetal alcohol syndrome, or a number of behavioral effects, even when physical development appears normal (Abel, 1981; Streissguth, Landesman-Dwyer, Martin, \& Smith, 1980). It is also known that children may react to alcohol in a more exaggerated fashion than adults, for example, by becoming agitated, nauseous, sleepy, or even comatose at blood concentrations as low as $0.05 \%$ (Bron, 1976). Yet, in spite of the fact that alcohol consumption by children has been documented in amounts that range from infrequent "sips" from an adult's beverage to regular

Chester F. Bergman constructed the figures. Technical assistance was provided by Janice Hauser, Danny Garland, and Mike Alvis. We thank W. F. Caul and the reviewers for helpful comments on earlier drafts of this paper, Bob Blaszezyk for providing some of the equipment, and $\mathrm{M}$. B. Fletcher for his continued support and encouragement. Correspondence may be sent to G. L. Osborne, Department of Psychology, Carson-Newman College, Jefferson City, Tennessee 37760. patterned use and drinking to intoxication (McCleary, 1974; Rodriquez-Lopez, 1979; Blane \& Hewitt, Note 1), the developmental toxicity of alcohol for the juvenile has not been systematically examined. If alcohol were determined to have enduring adverse effects during periadolescence, as some clinical case histories seem to suggest (e.g., Rubies-Prat, Miquel, \& Caralps, 1975), intervention strategies to reduce or eliminate use by children would be indicated.

The present study was undertaken as an initial probe into the question of enduring effects of alcohol on the juvenile. The purpose was to determine the effects of periadolescent alcohol exposure on passive avoidance performance in rats beginning at 20 days after treatment. The task was chosen because it is sensitive to prenatal effects of this drug (Riley, Lochry, \& Shapiro, 1979). Other features of the methodology (strain of rat, mode of administration, age at testing) were also derived from previous work on prenatal alcohol (Caul, Osborne, Fernandez, \& Henderson, 1979; Osborne, Caul, \& Fernandez, 1980).

\section{METHOD}

\section{Subjects}

The subjects were 48 female albino Sprague-Dawley rats derived from 11 litters born in the animal colony. At weaning, littermates were matched on the basis of body weight, ear-marked for identification, and assigned by the split-litter technique to either an untreated control or the $0-, 2-$, or 6-g treatment groups $(n=12)$.

\section{Procedure}

Treatments. Animals in the control group were weighed on alternate days from 30 to 40 days of age. The $0-, 2-$, and 6-8 groups were weighed and intubated with these amounts of alcohol per kilogram of body weight on the same alternate-day schedule. The solutions were equicaloric and consisted of a $20 \% \mathrm{w} / \mathrm{v}$ ethanol solution for the 6-g group, a sucrose and ethanol solution for the 2-g group, and a sucrose-only solution for the $0-8$ group.

During the study, the animals were housed 3-6 per cage in large metal cages (dimensions $=50.0 \times 50.0 \times 20.5 \mathrm{~cm}$ ). Lights were on in 
the animal room for $12 \mathrm{~h}$ daily, beginning at 7:00 a.m. Water was always available. Lab chow was provided daily, except that the 0 and 2-g groups, when it appeared that these animals were gaining more weight than those in the 6-g group, were not fed for approximately $12 \mathrm{~h}$ after their intubations. This procedure was used in order to hold body growth constant for the three treatment groups.

In terms of the acute effects of the alcohol treatments, the 2-g dose caused mild ataxia, whereas the 6-g dose induced marked ataxia and inactivity but not coma or death. Animals in all four groups gained the same amount of weight over the treatment period from 30 to 40 days of age $(F<1)$. Weight gain was also equivalent among groups from the end of treatment until behavioral testing began 20 days later $(F<1)$.

Behavioral measures. Passive avoidance testing began at 60 days of age. The procedure included a training phase, consisting of one trial per day for 10 consecutive days, and a retention phase, consisting of a single trial when the animals were 79 days old. The decision to use a set number of trials over days for all groups was based on preliminary work (Osborne, Butler, \& Hauser, Note 2) which had suggested that training animals to a performance criterion in a 1-day session might not be an adequately sensitive test for periadolescent alcohol effects.

A trial started when an animal was placed on a small platform in the white, lighted side of a Plexiglas conditioning box (box, 23.0 $\times 20.3 \times 19.5 \mathrm{~cm}$; platform, $7.7 \times 20.3 \times 1.7 \mathrm{~cm}$ ). After $20 \mathrm{sec}$, a door was raised permitting access to the black, unlighted side. If the animal stepped down from the platform into the dark side, placing all four feet on the grid floor, the door was lowered and an aversive stimulus was presented. The aversive stimulus was a loud 2-sec, 106-dB hissing noise produced by compressed air being released against the end wall of the conditioning box. The animal could, however, avoid the noise by remaining on the platform for $180 \mathrm{sec}$, at which time the door was lowered and the animal removed. This outcome was the passive avoidance response. The dependent measures for each trial were latency for the animal to step down from the platform (maximum score $=180 \mathrm{sec}$ ) and whether a successful passive avoidance response occurred.

\section{RESULTS}

Figure 1 displays the mean step-down latencies for each group. Over the 10 training trials, an impairment in performance was observed in 6-g animals. The 6-g group had shorter cumulative latencies than did either the control or the $0-\mathrm{g}$ group, whereas the latter two groups did not differ from each other. The overall one-way analysis of variance was significant $[F(3,44)=3.48, p<.025]$. The follow-up analysis, using Duncan's multiple-range test, indicated that the mean difference between the 6-g and control groups was significant $(\mathrm{p}<.01)$, as was the mean difference between the 6- and $0-g$ groups $(p<.05)$. The other group comparisons were not significant.

On the retention trial, which occurred 10 days after the training trials were completed, the impairment in passive avoidance performance of the 6-g group was still evident, as shown in Figure 1. The 6-g group had shorter latencies than any other group, while the control, 0-, and 2-g groups did not differ from each other. The overall one-way analysis of variance again was significant $[F(3,44)=6.20, p<.005]$. The Duncan tests revealed significant mean differences between the $6-\mathrm{g}$ and the control groups $(p<.01)$,

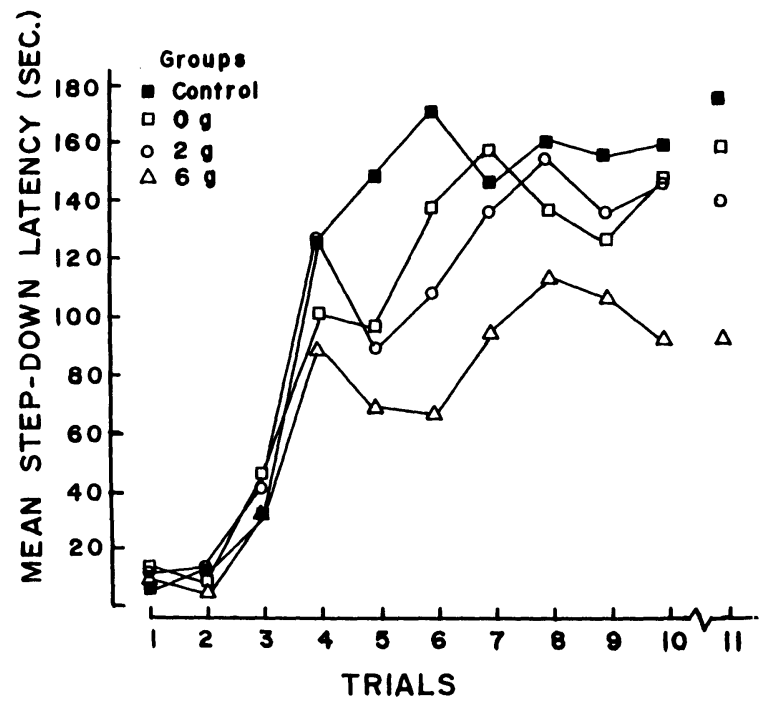

Figure 1. Mean step-down latencies in the passive avoidance task over the 10 training trials and on the retention trial (Trial 11).

between the 6- and $0-\mathrm{g}$ groups $(\mathrm{p}<.01)$, and between the 6- and $2-\mathrm{g}$ groups $(\mathrm{p}<.05)$. The other group comparisons were not significant.

One further analysis of the latency data was conducted to compare group performances on the last training trial with those on the retention trial (Trial 10 vs. Trial 11). The $4 \times 2$ analysis of variance indicated that all groups maintained their same level of responding across the retention interval, in that neither the trials effect nor the trials $\times$ treatment interaction was significant ( $F<1$ in each case).

The left panel of Figure 2 displays the mean number of passive avoidance responses made during the 10 training trials for each group. Although the 6-g
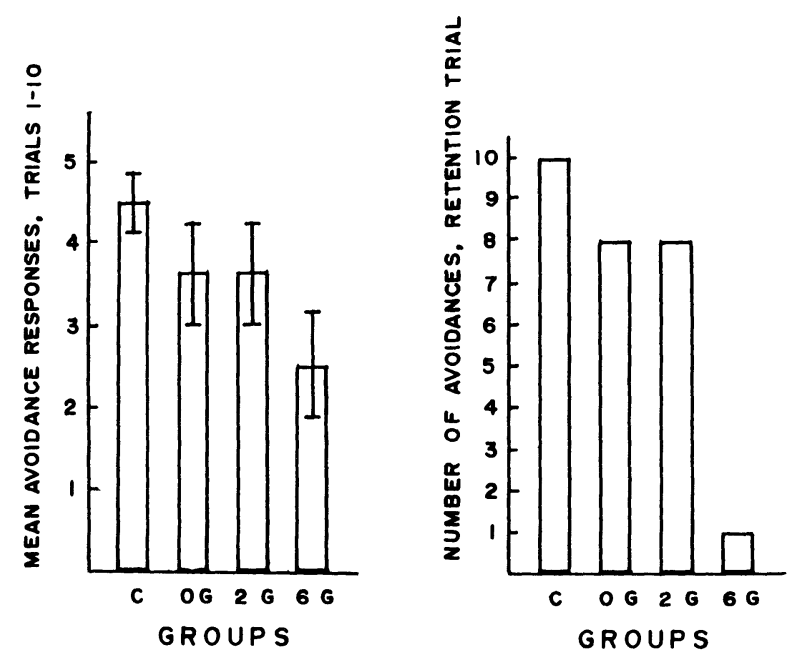

Figure 2. Left panel: Mean number of passive avoidance responses over the 10 training trials. Right panel: Number of animals making a passive avoidance response on the retention trial ( $n=12$ /group). 
group appears to have made fewer avoidances than the other groups, the overall analysis of variance for these data was not significant $[F(3,44)=2.08, .20>p$ $>.10]$. In like fashion, an analysis of group differences in mean trials to the first passive avoidance response was also nonsignificant $[\mathrm{F}(3,44)=1.76, .20>$ $\mathrm{p}>.10]$. Group means were $4.7 \pm 0.4$ for the control, $5.7 \pm 0.8$ for the $0-\mathrm{g}$ group, $5.2 \pm 0.5$ for the $2-\mathrm{g}$ group, and $6.8 \pm 1.0$ for the 6-g group.

As suggested in the right panel of Figure 2, however, group differences in avoiding the aversive noise did emerge on the retention trial, with the pattern the same as that found for retention latencies. The 6-g group had the fewest number of animals making a passive avoidance response, whereas the other groups did not differ from one another. The overall chi-square analysis was significant $\left[\chi^{2}(3)=15.83\right.$, $\mathrm{p}<.01]$. Each follow-up comparison (Fisher-Yates exact probability test) involving the 6-g group was significant $(p<.005)$, whereas none of the other group comparisons were.

\section{DISCUSSION}

These results show that alcohol administered during periadolsecence can impair the passive avoidance of rats tested 20-40 days later. It is interesting to note that prenatal alcohol exposure has been shown to have similar effects (Riley, Lochry, \& Shapiro, 1979). The interpretation that prenatal alcohol affects behavior in avoidance tasks by interfering with the animal's ability to inhibit responding (Riley, Lochry, Shapiro, \& Baldwin, 1979) may also explain the present data. This possibility seems strengthened by the findings that two measures of learning and memory, trials to first passive avoidance response and level of responding across the retention interval, were not significantly altered by the alcohol treatment. Thus, the enduring effects of periadolescent alcohol may not reflect problems in associative or memorial processes, but rather a performance dysfunction such as inability to inhibit responding.

In finding that periadolescent alcohol can have long-lasting effects on behavior, the present study suggests that risk of impaired development by this drug may not be limited to fetal and neonatal periods (e.g., Abel, 1981) but may extend through later postnatal periods as well. However, the question of whether periadolescence represents a "critical" time period for specific alcohol effects, or instead just another time period during immaturity when a general pattern of effects will occur, cannot be answered from this study. On the one hand, the present data do resemble those associated with prenatal alcohol exposure (Riley, Lochry, \& Shapiro, 1979), suggesting a general pattern of behavioral effects. On the other hand, brain development in periadolescence is, of course, quite different from that of the fetal period, in that basic neuroanatomical structures have already been established. It is interesting to speculate that the age-dependent maturation during periadolescence of certain dopaminergic systems involved in behavioral inhibition (Spear \& Brake, 1983) may be vulnerable to change by alcohol. Thus, it is conceivable that the underlying biologic effects responsible for the present data, as well as certain as-yet-undetected behavioral effects of periadolescent alcohol, relate to this specific exposure period.

One implication of this study is that intervention measures to reduce or eliminate drinking by children should be undertaken if clinical work is able to confirm the lasting adverse effect of periadolescent alcohol in humans. Since most children begin drinking in the home (Harrison, Bennett, \& Globetti, 1970), education of parents would be one recommended route for such intervention. A second, more general, implication is the possibility that other drugs with teratogenic potential may also be capable of affecting developmental processes in the juvenile as well as in the fetus and neonate (cf. Pizzi \& Barnhart, Note 3). Given the variety of drugs to which children may be exposed (e.g., Cohen, 1976), further research on enduring effects of drug administration during periadolescence is warranted.

\section{REFERENCE NOTES}

1. Blane, H. T., \& Hewitt, L. E. Alcohol and youth: An analysis of the literature 1960-1975. Unpublished manuscript (Contract ADM-281-75-0026), 1977. (Available from National Institute on Alcohol Abuse and Alcoholism, Rockville, Maryland 20852)

2. Osborne, G. L., Butler, A. C., \& Hauser, J. Behavioral effects of prepuberal ethanol exposure in rats. Paper presented at the meeting of the International Society for Developmental Psychobiology, Cincinnati, Ohio, November 1980.

3. Pizzi, W. J., \& Barnhart, J. E. Reproductive dysfunction following administration of monosodium glutamate to juvenile mice. Paper presented at the meeting of the Behavioral Teratology Society, Atlantic City, New Jersey, June 1983.

\section{REFERENCES}

Abel, E. L. Behavioral teratology of alcohol. Psychological Bulletin, 1981, 90, 564-581.

Bron, B. Current problems of alcohol misuse in children and adolescents. Zeitschrift für Allgemeinmedizin, 1976, 52, 505-511.

Caul, W. F., Osborne, G. L., Fernandez, K., \& Henderson, G. I. Open-field and avoidance performance of rats as a function of prenatal ethanol treatment. Addictive Behaviors, 1979, 4, 311-322.

Coнen, S. J. Drug use, misuse, and abuse incidents among elementary school children. Journal of Drug Education, 1976, 6, 247-253.

Harrison, D. E., Bennett, W. H., \& Globetti, G. Factors related to alcohol use among pre-adolescents. Journal of Alcohol Education, 1970, 15, 3-10.

MCCleARY, R. D. Child alcoholism as seen in the school in Illinois. International Journal of Offender Therapy and Comparative Criminology, 1974, 18, 182-186.

Osborne, G. L., Caul, W. F., \& Fernandez, K. Behavioral effects of prenatal ethanol exposure and differential early experience in rats. Pharmacology, Biochemistry \& Behavior, 1980, $12,393-401$. 
Riley, E. P., Lochry, E. A., \& Shapiro, N. R. Lack of response inhibition in rats prenatally exposed to alcohol. Psychopharmacology, 1979, 62, 47-52.

Riley, E. P., Lochry, E. A., Shapiro, N. R., \& Baldwin, J. Response perseveration in rats exposed to alcohol prenatally. Pharmacology Biochemistry \& Behavior, 1979, 10, 255-259.

Rodriquez-LOPEz, A. Alcohol ingestion by students of a Galician rural community. Drogalcohol, 1979, 4, 195-199.

Rubies-Prat, J., Miquel, C., \& Caralps, A. Delayed pituitary adrenal response in a child's alcoholic hypoglycemia. Annales d'Endocrinologie, 1975, 36, 223-224.

Schuste R, C. S. Biophysical development of the school-age child.
In C. S. Schuster \& S. S. Ashburn (Eds.), The process of human development. Boston: Little, Brown, 1980.

Spear, L. P., \& Brake, S. C. Periadolescence: Age-dependent behaviors and psychopharmacological responsivity in rats. Developmental Psychobiology, 1983, 16, 83-109.

Stre issguth, A. P., Landesman-Dwyer, S., Martin, J. C., \& Sмiтн, D. W. Teratogenic effects of alcohol in humans and laboratory animals. Science, 1980, 209, 353-361.

(Manuscript received April 20, 1983;

revision accepted for publication August 10, 1983.) 